\title{
A lady with excertional dyspnoea due to cardiac metastases
}

\author{
Rakul Nambiar K, Anoop TM* and Prakash NP \\ Department of Medical Oncology, Regional Cancer Centre, Trivandrum 695011, India
}

\begin{abstract}
Contrary to primary malignant cardiac tumors, metastatic tumors of the heart are relatively common. Cardiac metastases are usually the immediate cause of death in about one-third of such cases. They may cause cardiac failure, pericardial effusion and arrhythmia, with cardiac failure being the most common cause of death as a result of restrictive ventricular inflow and outflow tract obstruction, myocardial disease and pericardial constrictive disease. According to autopsy reports, cardiac metastases have been found in about $25 \%$ of patients with soft-tissue sarcoma. The incidence of cardiac metastasis has increased during recent years in view of better diagnostic tools and aggressive treatment of malignant tumors have led to longer survival of patients. Despite their increasing frequency, cardiac metastases are rarely diagnosed in living patients because other metastatic symptoms co-exist. We report a case of relapsed malignant peripheral nerve sheath tumor with symptomatic metastases to the heart. She was planned for surgery but in view of poor general condition, she was managed with palliative chemotherapy.
\end{abstract}

\section{Introduction}

Cardiac metastasis is a life-threatening condition and is usually the immediate cause of death in about one-third of such cases. However, it is very difficult to diagnose cardiac metastases because its lacks precise clinical features and such patients usually have other metastatic symptoms. Here, we report a case of a 50-year-old woman with relapsed malignant peripheral nerve sheath tumor who presented with symptomatic metastases to the heart

\section{Case report}

A 50-year-old woman treated for malignant peripheal nerve sheath tumor (MPNST) in right thigh four years back, presented with dyspnoea on exertion (New York Heart Association class -3). She denied chest pain and palpitations. She had undergone surgery for the primary tumor (MPNST) three years ago. Physical examination revealed diminished breath sounds in the right upper chest and cardiovascular system examination was normal. Chest radiograph demonstrated a large round opacity in the right upper lobe adjacent to the mediastinum. CT chest demonstrated a $7 \times 4 \times 6.5 \mathrm{~cm}$ lesion noted in the right posterior hemithorax with extension into adjacent left atrium for $20 \times 20 \times 16 \mathrm{~mm}$ (some bland thrombus also noted within the left atrium adjacent to tumour) (Figure 1). A computed tomography-guided needle biopsy was diagnostic of malignant peripheal nerve sheath tumor based on histopathology and immunohistochemistry. She was planned for surgical resection of the cardiac lesion. However she developed acute onset weakness of right side of body. CT brain revealed a metastatic lesion in left basal ganglia. In view of poor general condition, the patient was started on palliative chemotherapy with supportive medications and symptomatic management.

\section{Discussion}

Cardiac metastases usually appear in patients with advanced tumor disease; and at this stage of disease, most patients would have undergone some form of treatment for the primary tumor. The most common tumors with cardiac metastatic potential include malignant melanoma, carcinomas of the lung, esophagus and breast, malignant lymphoma, and leukemia [1-3]. The frequency of cardiac metastases is underestimated: varying from series to series and ranging from $12-25 \%$ of post-mortem patients who have died of malignancies [3,4]. In one series of 407 cases with cardiac metastases, $4.2 \%$ of these tumors were from a soft tisssue sarcoma primary [5].

Cardiac involvement may arise from hematogenous metastases, direct invasion from the adjacent mediastinal structures, or tumor growth into the vena cava and extension into the right atrium. Cardiac intracavitary metastases are infrequent and the atrium is more commonly involved than the ventricle [4]. These metastases are secondary to transvenous extension into the right atrium as a result of embolization or propagation along the vena cava.

The metastatic sites in the heart include the epicardium $(60 \%)$, myocardium (30\%) and endocardium (6\%), and intraventricular

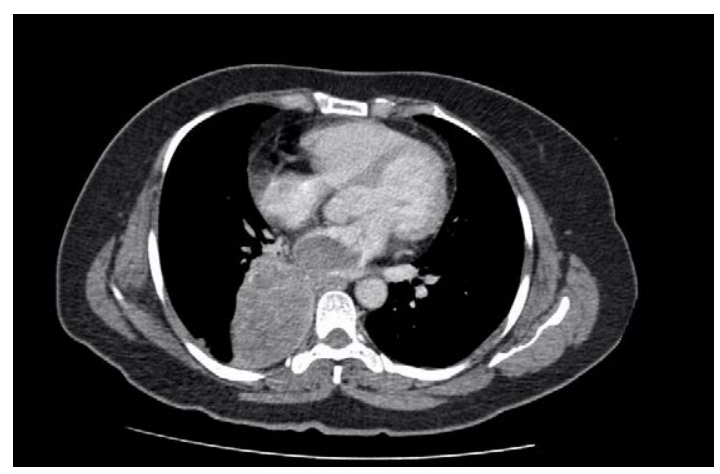

Figure 1. CT chest showed a lesion in right posterior hemithorax with extension into adjacent left atrium.

Correspondence to: Anoop TM, Assistant Professor, Department of Medical Oncology, Regional Cancer Centre, Trivandrum, 695011, India, Email : dranooptm@yahoo.co.in

Key words: cardiac metastases, sarcoma

Received: April 16, 2017; Accepted: May 08, 2017; Published: May 12, 2017 
tumour (3\%) [6-8]. Approximately $80 \%$ of intracavitary, endocardial or valvular type metastasis occur in the right heart chambers and rarely does metastasis occur in the left chambers. This is attributed to the filtering function of pulmonary circulation and the lower pressure in the right chambers [9].

Cardiac metastases are usually clinically silent, and hence most intracavitary tumors are found on autopsy. Only less than $10 \%$ present with symptoms of cardiac dysfunction [3]. However, right-sided metastases can lead to pulmonary tumor emboli with progressive cor pulmonale over weeks to months [6,7]. Occlusion of the pulmonary vasculature with tumor cells and associated thrombus would present as a subacute and progressive clinical scenario. Identifying a diagnosis of tumor embolism would be challenging as the diagnosis is usually under-recognized and imaging findings are nonspecific.

Treatment of cardiac metastses is often palliative in view of widespread disease. Although rare, single nodules may be amenable to resection Indications for surgery in patients with metastatic cardiac tumors shouldt be carefully considered, particularly for elderly patients, asymptomatic patients and with other metastatic lesions [10,11].

In conclusion, metastases to the heart should also be considered in the differential of cardiac lesions detected by echocardiography in pateints with malignancy. Failure to recognize cardiac metastatic disease would ultimately lead to progressive cardiac failure and death if not treated.

\section{References}

1. Hallahan DE, Vogelzang NJ, Borow KM, Bostwick DG, Simon MA (1986) Cardiac metastases from soft-tissue sarcomas. J Clin Oncol 4: 1662-1669. [Crossref]

2. Bussani R, De-Giorgio F, Abbate A, Silvestri F (2007) Cardiac metastases. J Clin Pathol 60: 27-34. [Crossref]

3. Reynen K, Köckeritz U, Strasser RH (2004) Metastases to the heart. Ann Oncol 15 375-381. [Crossref]

4. Cuadrado M, Garcia-Camarero T, Exposito V, Val-Bernal JF, Gomez-Roman JJ, et al. (2007) Cardiac intracavitary metastasis of a malignant solitary fibrous tumor: case report and review of the literature on sarcomas with left intracavitary extension. Cardiovasc Pathol 6: 241-247.

5. Mukai K, Shinkai T, Tominaga K, Shimosato Y (1988) The incidence of secondary tumors of the heart and pericardium: a 10-year study. Jpn J Clin Oncol 18: 195-201. [Crossref]

6. Abraham KP, Reddy V, Gattuso P (1990) Neoplasms metastatic to the heart: review of 3314 consecutive autopsies. Am J Cardiovasc Pathol 3: 195-198. [Crossref]

7. Butany J, Leong SW, Carmichael K, Komeda M (2005) A 30-year analysis of cardiac neoplasms at autopsy. Can J Cardiol 21: 675-680. [Crossref]

8. Klatt EC, Heitz DR (1990) Cardiac metastases. Cancer 65: 1456-1459. [Crossref]

9. Byun SW, Park ST, Ki EY, Song H, Hong SH, et al. (2013) Intracardiac metastasis from known cervical cancer: a case report and literature review. World J Surg Oncol 11: 107. [Crossref]

10. Veinot JP, Ford SE, Price RG (1992) Subacute cor pulmonale due to tumor embolization. Arch Pathol Lab Med 116: 131-134. [Crossref]

11. Roberts KE, Hamele-Bena D, Saqi A, Stein CA, Cole RP (2003) Pulmonary tumor embolism: a review of the literature. Am J Med 115: 228-232. [Crossref]

Copyright: (C2017 Rakul Nambiar K. This is an open-access article distributed under the terms of the Creative Commons Attribution License, which permits unrestricted use, distribution, and reproduction in any medium, provided the original author and source are credited. 